\title{
UNBK: TRANSFORMASI SISTEM EVALUASI STANDAR NASIONAL DI ERA REVOLUSI INDUSTRI 4.0
}

\author{
Syarif Hidayatullah*, Ismail Marzuki**, Lukmanul Hakim*** \\ syahid449@gmail.com, ismailmarzuki@umt.ac.id, lukman@umt.ac.id \\ * Mahasiswa Magister PAI Program Pascasarjana, Universitas Muhammadiyah Tangerang \\ **Dosen Fakultas Agama Islam, Universitas Muhammadiyah Tangerang \\ ***Dosen Fakultas Agama Islam, Universitas Muhammadiyah Tangerang
}

\begin{abstract}
Education is the process of transferring knowledge. In the process, it is necessary to design a quality curriculum. In the curriculum, one of the essential things is evaluation. Educators can make evaluations to students in order to obtain information on student development. In the national education system, the state pays great attention to education. The state's attention in education is to hold a national exam to equalize the quality of education in Indonesia. The national standard evaluation system is still changing in terms of terms and technicalities. Recently, computer-based evaluation systems are the latest step and innovation. Especially in the current era of the industrial revolution 4.0, digitization systems are in all aspects of life, including in the world of education. Since 2014, the national standard education evaluation system began using the online examination system. Although in 2014, not all of the schools in Indonesia were able to conduct and access computer-based examinations with the internet network. The program requires sufficient time for socialization and technical preparation. The spirit of revolution 4.0 is marked by building a digitalized national standard evaluation system. Even in response to the development of the Industrial Revolution era 4.0, Indonesia has made innovative breakthroughs in the world of education, namely the Computer Based National Examination (UNBK) system.
\end{abstract}

Keywords: Evaluation, UNBK, Revolution 4.0

\section{A. PENDAHULUAN}

Problematika yang dihadapi manusia sejak zaman dahulu sampai sekarang adalah masalah moral. Dalam perjalananya, manusia mengalami siklus perubahan positif terjadi yang dilatar belakangi dengan meningkatnya daya pikir manusia. Meningkatnya intelektualitas itu tidak lepas dari peranan pendidikan. Pendidikan dalam kehidupan memiliki kedudukan yang sangat penting.(Mukhtarom et al., 2019)

Menurut A. Tafsir dalam Filsafat Pendidikan Islam (2014:39) pendidikan berlangsung seumur hidup dengan mengesampingkan apakah dimulai sejak lahir atau setelah lahir.(Tafsir, 2014) Maka pendidikan dapat dikatakan sebagai pertolongan. Dan dari sisi lain pendidikan ialah segala sesuatu yang mempengaruhi seseorang. Dengan demikian pendidikan harus berlangsung seumur hidup karena manusia selama masih hidup ia selalu mendapat pengaruh dari pihak lain. Sisi lain bahwa pendidikan merupakan usaha menolong orang agar ia mampu menyelesaikan masalah yang dihadapinya. Jadi, selama manusia masih menghadapi masalah yang harus diselesaikan selama itu pula ia masih menjalani pendidikan, sementara manusia tidak pernah tidak menghadapi masalah. Jadi, karena manusia selalu menghadapi masalah maka selama itu pula ia memerlukan pendidikan. 
Islam memberikan perhatian besar tehadap pendidikan. Menurut Islam, pendidikan adalah kewajiban bagi penganutnya. Dan dalam pandangan Islam pendidikan adalah cara manusia memperoleh kebahagian dunia dan akhirat. Proses pendidikan telah dicontohkan Allah SWT kepada Nabi Adam AS. Yang tertera dalam Al-Quran, Allah SWT berfirman:

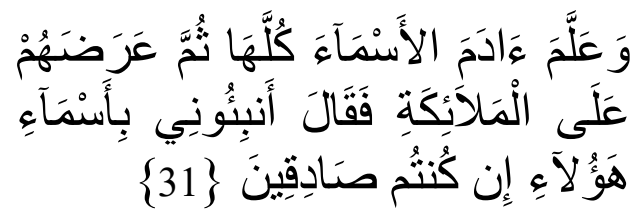

Dan Dia mengajarkan kepada Adam nama-nama (benda-benda) seluruhnya, kemudian mengemukakannya kepada para Malaikat lalu berfirman:"Sebutkanlah kepada-Ku nama benda-benda itu jika memang kamu orang yang benar!", (QS. Al-Baqoroh :31)

Dengan demikian pendidikan bukanlah perkara baru dalam kehidupan manusia. Bahkan dalam Islam, sedari manusia itu dilahirkan ke dunia, hal yang pertama adalah mengazankan bayi yang mengandung nilai filosofi. Dikumandangkan azan ke telinga sang bayi sebagai pondasi awal proses pendidikan, mengajarkan kalimat yang toyibah padanya sejak dini. Nilai-nilai pendidikan dalam Islam ditegaskan Nabi Muhammad SAW dalam haditsnya.

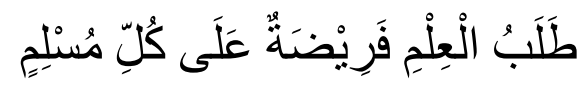

Mencari ilmu itu adalah wajib bagi setiap muslim laki-laki maupun muslim. (HR. Ibnu Abdil Barr)

Kewajiban mencari ilmu kepada muslim adalah langkah Rasullah SAW dalam berdakwah dan sutu ekspektasi agar umat Islam dapat menjadi umat yang memiliki kualitas dan integritas dalam beragama dan memberikan kemanfaatan bagi orang lain. Dalam rangka meningkat daya intelektualitas muslim pendidikan Islam harus mampu berinovasi dan menjawab tantang disetiap perkembangan zaman. Transformasi pendidikan Islam yang lebih terbuka dengan memutus stigma dikotomi ilmu pengetahuan dalam Islam. Maka konsep integrasi ilmu merupakan upaya pembaharuan dalam pendidikan, dengan harapan dapat membangun pendidikan yang berkemajuan.

Pendidikan yang baik adalah pendidikan yang terencana dan memiliki tujuan yang jelas. Usaha mewujudkan pendidikan yang berkualitas maka perlu disusun kurikulum. Di Indonesia terdapat kurikulum yang berstandar nasional dan kurikulum tingkat satuan pendidikan. Yang pada prakteknya kedua macam kurikulum ini dikombinasikan untuk mencapai citacita pendidikan di Indonesia. Menurut Rusydi Ahmad Thuaimah (1989:61) dalam menyusun kurikulum tersebut, harus diperhatkan empat unsur, yaitu: materi ( $A l$ Muhtawa), metode (Al-Thoriqoh), evaluasi (Al-Taqwiim) dan tujuan (Al-Hadaf). (Thuaimah, 1989)

Salah satu hal yang terpenting dari kurikulum adalah evaluasi. Evaluasi yakni berupa bagian dari proses yang harus dilaksanakan pada aktifitas pendidikan. Evaluasi merupakan salah satu cara untuk mengukur tingkat keberhasilan belajar dalam satuan pendidikan. Bahkan evaluasi merupakan tolok ukur kesuksesan sebuah negara dalam menyelenggarakan pendidikan. Pendidikan tidak dapat dipisah dengan sistem evaluasi. Proses pembelajaran yang baik harus mengadakan evaluasi dalam rangka mengetahui hasil belajar dan tingkat keberhasilan bagi penyelenggara pendidikan. Dalam kegiatan belajar dan mengajar di sekolah, evaluasi ini dilakukan dengan mengadakan ujian (assesment). Seyogyanya, seorang pendidik memberikan penilaian pada setiap akhir dari satu bab materi yang telah dipelajari atau disebut Ulangan Harian (UH), Penilaian Tengah Semester (PTS), dan Penilaian Akhir Semester (PAS). Serta evaluasi yang dilakukan secara nasional baik itu UASBN/UAMBN ataupun Ujian Nasional (UN).

Memasuki era revolusi 4.0, yang menuntut pada penggunaan jaringan internet pada setiap aspek kehidupan. 
Kemajuan zaman yang ditandai kemajuan teknologi ini, tentu bertujuan untuk mempermudah dalam beriteraksi. Tidak menutup kemungkinan, dalam ranah pendidikan hal tersebut pun terjadi. Bahkan dalam merespon perkembangan di era revolusi Industri 4.0, Indonesia telah melakukan terobosan inovatif dalam dunia pendidikan. Salah satu yang mendasar adalah sistem Ujian Nasional Berbasis Komputer (UNBK).

\section{B. METODE PENELITIAN}

Penelitian ini menggunakan metode library research yang menggunakan metode penelitian kualitatif. Library research merupakan salah satu jenis metode penelitian kualitatif. Riset pustaka memanfaatkan sumber data sekunder untuk memperoleh data penelitian.

\section{PEMBAHASAN}

\section{Ujian Nasional dalam Perspektif Evaluasi Pendidikan}

Evaluasi dalam pengertian umum adalah pengukuran dan penilaian. Dengan evaluasi, maka suatu kegiatan dapat diketahui atau ditentukan taraf kemajuannya. (Marzuki et al., 2019). Dalam Al-Qur'an Allah SWT menyebutkan proses evaluasi yang terjadi pada manusia. Yang mengilustrasikan bahwa evaluasi Allah SWT berikan bertujuan mengetahui orang yang benar keimanannya dan yang dusta.

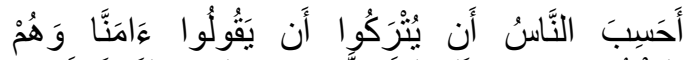

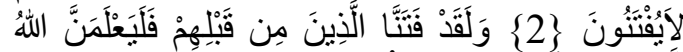

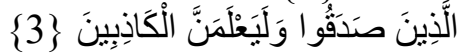

Apakah manusia itu mengira bahwa mereka dibiarkan (saja) mengatakan: "Kami telah beriman", sedang mereka tidak diuji lagi? (2) Dan sesungguhnya Kami telah menguji orang-orang yang sebelum mereka, maka sesungguhnya Allah mengetahui orang-orang yang benar dan sesungguhnya Dia mengetahui orangorang yang dusta. (QS. Al-Ankabut 2-3)

Dalam ayat lain, Allah SWT menginformasikan tentang bentukbentuk evaluasi dan tujuan dari evaluasi tersebut.

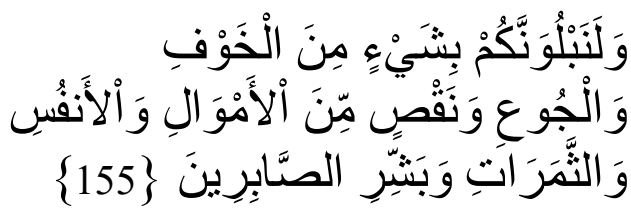

Dan sungguh akan Kami berikan cobaan kepadamu, dengan sedikit ketakutan, kelaparan, kekurangan harta, jiwa dan buah-buahan. Dan berikanlah berita gembira kepada orang-orang yang sabar. (QS. AlBaqoroh:155)

Dalam mengadakan evaluasi meliputi dua langkah, yakni mengukur dan menilai. Dalam istilah asingnya, pengukuran adalah measurement, sedangkan penilaian adalah evaluation. Dalam kata bahasa Indonesia evaluasi berarti menilai tetapi dilakukan dengan mengukur terlebih dahulu (Arikunto, 2013:3). Evaluasi pendidikan memiliki peranan penting untuk mencapai target dari pendidikan. Evaluasi terkadang dikaitkan dengan hasil belajar. (Arikunto, 2013)

Menurut Majid Irsan Al-Kaylani dalam Manahij Al-Tarbiyah AlIsamiyah wa Al-Murobbun Al-Aamilun Fiiha (1995:42) mengatakan evaluasi (Al-Taqwim) adalah sebuah proses pengumpulan data dalam memperoleh hasil pembelajaran sesuai tujuan yang ditargetkan, yang dapat dilihat dari segi perubahan dan perkembangan sikap atau perbuatan peserta didik kemudian penilaian perkembangan tersebut diukur dengan pencapaian dari tujuan pendidikan yang telah ditentukan.(AlKaylani, 1995)

Dengan adanya pengertian tersebut, menegaskan bahwa evaluasi merupakan hal urgen dalam sebuah 
kurikulum. Maka dalam penyusunan kurikulum harus memperhatikan aspek yang berkaitan dengan kegiatan pembelajaran. Dalam pembelajaran yang terjadi di dalam kelas, pendidik memiliki tanggung jawab besar atas perkembangan peserta didik. Dan pendidik merupakan pihak yang paling bertanggung jawab atas hasilya. Dengan demikian pendidik harus dibekali dengan pengetahuan tentang evaluasi sebagai ilmu yang mendukung tugasnya. Dengan adanya evaluasi tersebut, pendidik dapat mengetahui hasil dari proses pembelajaran yang telah dilakukan. Apakah sesuai dengan target yang dirumuskan atau tidak. Sementara instansi pendidikan diumpamakan sebagai sarana mengolah sesuatu, dan peserta didik dapat diumpamakan sebagai sesuatu yang siap diolah. Peranan instansi pendidikan tersebut harus dapat memberikan hasil yang siap diberdayakan dan bermanfaat untuk orang banyak.

Pada prisipnya evaluasi berkaitan erat dengan tujuan dan kegiatan pembelajaran, yang semua itu saling berkaitan. Triangulasi tersebut menjadi satu kesatuan dalam mendapatkan informasi terkait perkembangan hasil pembelajaran. Hubungan antara kegiatan belajar mengajar dengan tujuan pembelajar, menjadi tolok ukur pendidik dalam mengarahkan peserta didik dengan tujuan pembelajaran yang dicapai. Kegiatan pembelajaran perlu dilakukan evaluasi. Dan alat evaluasi itu mengacu pada tujuan pembelajaran.

Ada dua cara untuk melakukan evaluasi, yaitu dilakukan dengan teknik tes dan non-tes. Arikunto (2013:46) mengutip dari Webster's Collegiate menyatakan bahwa tes adalah serentetan pertanyaan atau latihan atau alat lain yang digunakan untuk mengukur keterampilan, pengetahuan, intelegensi, kemampuan atau bakat yang dimiliki oleh individu atau kelompok.(Arikunto, 2013)
Melalui teknik tes ini, dapat dilakukan tes diagnostik, formatif dan sumatif. Bekaitan dengan UN yang dilakukan di sekolah-sekolah Indonesia. maka UN merupakan bagian evaluasi yang menggunakan teknik tes sumatif. Tes sumatif ini dapat dilaksanakan setelah berakhirnya pemberian sekelompok atau sebuah program yang lebih besar.

$$
\text { Menurut Haidar Baghir }
$$

(2019:165), UN bisa saja masih diperlukan yakni sebagai alat assesment kualitas pendidikan kita.(Bagir, 2019) Atau sebagai alat evaluasi proses belajar. Dengan syarat sebagai berikut: Pertama, UN tidak ditempatkan secara sendirian menentukan kelulusan. Kedua, materi soal-soal UN dirancang tepat dan relevan dengan tujuan pendidikan. Ketiga, soal-soal UN tidak hanya mencakup mata pelajaran, melainkan semua pelajaran dan faktorfaktor yang menyangkut Multi Intelligences. Keempat, cara evaluasi harus dapay memberikan tempat yang sama penting terhadap ranah afektif (sikap) dan psikomotorik (praktik), disamping ranah kognitif (mental).

Ujian Nasional biasa disingkat UN/UNAS adalah sistem evaluasi standar pendidikan dasar dan menengah secara nasional dan persamaan mutu tingkat pendidikan antar daerah yang dilakukan oleh pusat penilaian pendidikan dalam hal ini dilakukan oleh negara melalui Kementrian Pendidikaan Nasional. Ujian nasional dilakukan di Indonesia sejak tahun 1950 sampai sekarang. Bahkan dengan peraturan baru sistem ujian nasional yang dilaksanakan berbasis komputer atau dikenal sebagai Ujian Nasional Berbasis Komputer (UNBK).

Dikutip dari laman Kementrian Pendidikan dan Kebudayaan bahwa Ujian Nasional Berbasis Komputer (UNBK) disebut juga Computer Based Test (CBT) adalah sistem pelaksanaan ujian nasional dengan menggunakan komputer sebagai media ujiannya. Dalam pelaksanaannya, UNBK berbeda 
dengan sistem ujian nasional berbasis kertas atau Paper Based Test (PBT) yang selama ini sudah berjalan.

Penyelenggaraan

UNBK pertama kali dilaksanakan pada tahun 2014 secara online dan terbatas di SMP Indonesia Singapura dan SMP Indonesia Kuala Lumpur (SIKL). Hasil penyelenggaraan UNBK pada kedua sekolah tersebut cukup menggembirakan dan semakin mendorong untuk meningkatkan literasi peserta didik terhadap TIK (Teknologi Informasi dan Komunikasi). Selanjutnya secara bertahap pada tahun 2015 dilaksanakan rintisan UNBK dengan mengikutsertakan sebanyak 556 sekolah yang terdiri dari 42 SMP/MTs, 135 SMA/MA, dan 379 SMK di 29 Provinsi dan Luar Negeri.

Pada tahun 2016 dilaksanakan UNBK dengan mengikutsertakan sebanyak 4.382 sekolah yang tediri dari 984 SMP/MTs, 1.298 SMA/MA, dan 2.100 SMK. Jumlah sekolah yang mengikuti UNBK tahun 2017 melonjak tajam menjadi 30.577 sekolah yang terdiri dari $11.096 \mathrm{SMP} / \mathrm{MTs}, 9.652$ SMA/MA dan 9.829 SMK. Meningkatnya jumlah sekolah UNBK pada tahun 2017 ini seiring dengan kebijakan resources sharing yang dikeluarkan oleh Kemendikbud yaitu memperkenankan sekolah yang sarana komputernya masih terbatas melaksanakan UNBK di sekolah lain yang sarana komputernya sudah memadai.

Penyelenggaraan UNBK saat ini menggunakan sistem semi-online yaitu soal dikirim dari server pusat secara online melalui jaringan (sinkronisasi) ke server lokal (sekolah), kemudian ujian peserta didik dilayani oleh server lokal (sekolah) secara offline. Selanjutnya hasil ujian dikirim kembali dari server lokal (sekolah) ke server pusat secara online dengan cara meng-upload.

\section{Sejarah Ujian Nasional di Indonesia}

Dalam catatan sejarah pendidikan nasional, sistem evaluasi berstandar nasional banyak mengalami perubahan istilah dan perubahan teknik ujian. Dapat dijumpai juga polemik dalam penyelenggaraanya. Ujian nasional diberlakukan di Indonesia mulai tahun 1950 dan telah beberapa kali berganti sistem dan format ujian. Dikutip dari laman: https://www.padamu.net/sejarah-ujiannasional-indonesia. Berikut sejarah perjalanan ujian nasional Indonesia:

a. Periode 1950-1965

Pada periode ini, ujian nasional disebut dengan Ujian Penghabisan. Materi ujian dibuat oleh Departemen Pendidikan, Pengajaran, dan Kebudayaan menerapkan format ujian yaitu seluruh soal dikerjakan dalam bentuk esai atau isian. Hasil ujian diperiksa di pusat rayon yang telah ditentukan.

b. Periode 1965-1971

Pada periode ini, ujian nasional disebut dengan Ujian Negara. Waktu dan materi ujian ditentukan oleh pemerintah pusat. Bahan ujian adalah seluruh mata pelajaran. Artinya materi yang diuji adalah semua mata pelajaran yang diajarkan kepada peserta didik.

c. Periode 1972-1979

Pada periode ini, pemerintah pusat hanya menyusun pedoman dan panduan ujian nasional yang bersifat umum. Penyelenggaraan ujian nasional dilakukan oleh masingmasing sekolah atau atau sekelompok sekolah dengan waktu dan materi yang dapat disesuaikan. Dengan demikian materi dan hasil ujian dilakukan masing-masing sekolah atau kelompok.

d. Periode 1980-2001

Pada periode ini, ujian nasional disebut dengan EBTANAS (Evaluasi Belajar Tahap Akhir Nasional) dan EBTA (Evaluasi Belajar Tahap Akhir). Kelulusan peserta didik ditentukan oleh 
kombinasi nilai EBTANAS yang dikoordinasi oleh pemerintah pusat dan EBTA yang dikoordinasikan oleh pemerintah daerah serta ditambah nilai ujian harian yang tertera di buku rapor. Pada periode ini dikenal dengan DANEM (Daftar Nilai Ebtanas Murni) yaitu hasil nilai ebtanas apa adanya. Namun kelulusan berdasarkan nilai rata-rata seluruh mata pelajaran yang diujikan meskipun ada peserta didik yang mendapat nilai dibawah tiga pada mata pelajaran tertentu.

e. Periode 2002-2004

Pada periode ini, ujian nasional disebut dengan Ujian Akhir Nasional (UAN) menggantikan Ebtanas. Standar kelulusan UAN setiap tahun berbeda-beda. Pada UAN 2002 kelulusan ditentukan oleh nilai mata pelajaran secara individual. Pada UAN 2003 standar kelulusan adalah 3.01 pada setiap mata pelajaran dan nilai rata-rata minimal 6.00. Soal ujian dibuat oleh Depdiknas dan pihak sekolah tidak dapat mengangkat nilai UAN. Para peserta didik yang tidak/belum lulus masih diberi kesempatan mengulang selang satu minggu sesudahnya. Pada UAN 2004, kelulusan peserta didik didapat berdasarkan nilai minimal pada setiap mata pelajaran 4.01 dan tidak ada nilai rata-rata minimal. Pada mulanya UAN 2004 ini tidak ada ujian ulang bagi yang tidak/belum lulus. Namun setelah mendapat masukan dari berbagai lapisan masyarakat, akhirnya diadakan ujian ulang.

f. Periode 2005-2012

Pada periode ini, ujian nasional disebut dengan Ujian Nasional (UN) menggantikan Ujian Akhir Nasional (UAN). Standar kelulusan Ujian Nasional (UN) setiap tahun juga berbeda. Pada UN 2005 minimal nilai untuk setiap mata pelajaran adalah 4.25. Pada UN 2005 ini para peserta didik yang belum lulus pada tahap I boleh mengikuti UN tahap II hanya untuk mata pelajaran yang belum lulus. Pada UN 2006 standar kelulusan minimal adalah 4.25 untuk tiap mata pelajaran yang diujikan dan rata-rata nilai harus lebih dari 4.50 dan tidak ada ujian ulang. Pada UN 2007 ini tidak ada ujian ulang. Dan bagi yang tidak lulus disarankan untuk mengambil paket $\mathrm{C}$ untuk meneruskan pendidikan atau mengulang UN tahun depan. Pada UN 2008 mata pelajaran yang diujikan lebih banyak dari yang semula tiga, pada tahun ini menjadi enam. Pada UN 2009 standar untuk mencapai kelulusan, nilai rata-rata minimal 5.50 untuk seluruh mata pelajaran yang di-UN-kan, dengan nilai minimal 4.00 untuk paling banyak dua mata pelajaran dan minimal 4.25 untuk mata pelajaran lainnya. Pada UN 2010 standar kelulusannya adalah, memiliki nilai rata-rata minimal 5.50 untuk seluruh mata pelajaran yang diujikan, dengan nilai minimal 4.0 untuk paling banyak dua mata pelajaran dan minimal 4.25 untuk mata pelajaran lainnya. Khusus untuk SMK, nilai mata pelajaran praktek kejuruan minimal 7.00 dan digunakan untuk menghitung rata-rata UN. Pada UN 2011 dan 2012 Nilai kelulusan peserta didik masih tetap yaitu 5,5. Begitu juga soal tetap dibagi dalam enam macam paket, yakni lima soal utama dan satu cadangan bila ada soal tak lengkap atau rusak.

g. Periode 2014-sekarang

Pada tahun 2014, pemerintah melalui Kementrian Pendidikan dan Budaya memberikan terobosan baru dalam sistem ujian nasional berbasiskan Komputer dan menggunakan jaringan internet.

\section{UNBK Sebagai Modernisasi Sistem Evaluasi Pendidikan Nasioanal di Era Revolusi Industri 4.0}


Perkembangan masyarakat dunia pada umumnya dan Indonesia pada khusunya mau tidak mau akan menuju kepada masyarakat informasi (information society) sebagai kelanjutan atau perkembangan dari masyarakat industri dan modern. Jika masyarakat modern memiliki ciri-ciri rasional, berorientasi kedepan, bersikap terbuka, menghargai waktu, kreatif, mandiri dan inovatif, maka pada masyarakat informatif ciri-ciri tersebut belum cukup.

Menurut Nata (2001:81) pada masyarakat informasi, manusia selain memiliki ciri-ciri modern, juga harus memiliki ciri-ciri lain yaitu menguasasi dan mampu mendayagunakan arus informasi, mampu bersaing, terus menerus belajar, mampu menjelaskan, imajinatif, mampu mengubah tantangan menjadi peluang, dan menguasai berbagai metode dalam memecahkan masalah yang dihadapi.(Nata, 2001)

Pada masyarakat informasi peranan media dan teknologi memiliki peranan penting. Bahkan dengan adanya teknologi internet dapat mengubah corak kehidupan lokal dan nasional menuju masyarakat yang bercorak internasional. Yang memberi dan mendapatkan informasi dalam jangkauan yang lebih luas. Disi lain, kemajuan dalam bidak teknologi dapat berpengaruh pada kejiwaan dan kepribadian masyarakat. Masyarakat yang mampu bertahan mereka yang memiliki pandangan ke depan, mampu menggunakan kemajuan teknologi dalam menjalin interaksi dalam bidang apapun. Begitu juga, pendidikan di era informasi yang penuh dengan kemajuan teknologi atau digitalisasi harus mampu menciptakan manusia yang berkualitas dibidang teknologi.

Di dalam menyahuti perkembangan era globalisiasi menurut Daulay (2012: 130-131), perlu mendapatkan perhatian dalam beberapa hal. Pertama, kurikulum, permasalahan yang muncul adalah bagaimanakah yang adaptif untuk dunia global tersebut. Ilmu-ilmu basic tetap ilmu perennial knowledge, tetapi bagaimana agar outputnya bernuansa global. Kedua, kualitas, sudah dimaklumi bahwa era global adalah era kompetitif yang mengedepankan keunggulan. Ketiga, kelembagaan, artinya lembaga harus mampu membangun sebuah sistem pendidikan dan merubah institusi dalam sekup yang lebih besar dan modern.(Daulay, 2012)

Menghadapi era revolusi industri 4.0, pemerintah Indonesia membuat sebuah road map yang dinamakan "making Indonesia 4.0. dalam road map ini terdapat lima teknologi utama yang menopang industry 4.0 yakni Internet of Thing (IoT), Artificial Intelligence (AL), Human-Machine Interface, teknologi robotic dan sensor, seta teknologi 3D printing". Kelima teknologi memiliki keterkaitan dengan informatika.(Utami, 2019)

Keterkaitan sistem informatika dengan Revolusi 4.0 memberikan solusi atas masalah pada ujian nasional (UN) yang terkadang menjadi persoalan pendidikan yang datang di setiap tahunnya. Masalah yang sering dialami adalah pendistribusian naskah soal ujian tersebut. Maka dengan adanya Ujian Nasional Berbasis Komputer (UNBK) menjadi solusi atas masalah tersebut. Kehadiran UNBK bukan tanpa masalah dan hambatan dalam mentransformasi sistem evaluasi berstandar nasional. Terkait dengan masalah yang muncul dengan sistem UNBK ini antara lain adalah masalah sarana atau media ujian seperti perangkat komputer dan jaringan internet. Inilah yang perlu juga diperhatikan dengan mencari solusi terkait kendala teknis dan lain.

\section{KESIMPULAN}

Dari pembahasan tentang UNBK sebagai Transformasi Sistem Evaluasi Standar Nasional Di Era Revolusi Industri 4.0 di atas dapat 
diambil kesimpulan, beberapa hal berikut:

1. Evaluasi pendidikan merupakan bagian dar kurikulum, oleh karena itu evaluasi perlu dilakukan agar memperoleh informasi terhadap perkembangan atau keberhasilan peserta didik.

2. Sejarah panjang terkait Ujian Nasioanal (UN) di Indonesia memberikan pelajaran berharga bahwa menjaga penyetaraan kualitas pendidikan disetiap daerah di Indonesia perlu diperhatikan.

3. Memasuki era revolusi industri 4.0, dunia pendidikan perlu meningkatkan sarana yang mendukung kegiatan belajar mengajar yang lebih modern.

4. UNBK merupakan langkah responsif memasuki era revolusi 4.0 yang ditandai dengan sistem digital dan menggunakan teknologi internet.

\section{DAFTAR PUSTAKA}

Al-Kaylani, M. A. (1995). Manahij AlTarbiyah Al-Isamiyah wa AlMurobbun Al-Aamiluna Fiiha. Beirut: Aalam Al-Kutub.

Arikunto, S. (2013). Dasar-dasar Evaluasi Pendidikan. Jakarta: Bumi Aksara.

Bagir, H. (2019). Memulihkan Sekolah Memulihkan Manusia. Jakarta: Mizan.

Daulay, H. P. (2012). Pendidikan Islam dalam Sistem Pendidikan Nasional di Indonesia. Jakarta: Kencana Prenada Media Group.

Marzuki, I., Hakim, L., Fakultas, D., Islam, A., Tangerang, U. M., Fakultas, D., ... Tangerang, U. M. (2019). EVALUASI PENDIDIKAN ISLAM. 1(1), 77-84.

Mukhtarom, A., Arwen, D., Kurniyati, E., Magister, D., Agama, P., Tangerang, U. M., ... Tangerang, U. M. (2019). Urgensi civic education dalam kehidupan bernegara. 1(2), 152-162.

Nata, A. (2001). Paradigma Pendidikan Islam. Jaka: Grasindo.

Tafsir, A. (2014). Filsafat Pendidikan
Islam; Integrasi Jasmani, Rohani, dan kalbu Memanusiakn Manusia. Bandung: Remaja Rosdakarya.

Thuaimah, R. A. (1989). Ta'limul Arobiyah Li Ghoiri Ntiqiin Biha Manahujuhu Wa Asalibuhu. Ribath: ISESCO.

Utami, E. (2019). Digit Is Me: Inpirasi Islam dalam Ilmu Pengetahuan dan Teknologi. Yogyakarta: Media Publisher.

https://www.padamu.net/sejarah-ujiannasional-indonesia, diakses 15 Februari 2020. 